\title{
Visualization and quantification of 4D blood flow distribution and energetics in the right ventricle
}

\author{
Carl Johan Carlhäll ${ }^{1}$, Alexandru G Fredriksson ${ }^{1 *}$, Jakub Zajac ${ }^{1}$, Jonatan Eriksson ${ }^{1}$, Petter Dyverfeldt11 ${ }^{1}$, Jan Engvall ${ }^{1}$, \\ Ann F Bolger ${ }^{2}$, Tino Ebbers ${ }^{1}$
}

From 2011 SCMR/Euro CMR Joint Scientific Sessions

Nice, France. 3-6 February 2011

\section{Background}

Right ventricular (RV) function has important prognostic value in both right- and left-sided acquired and congenital heart diseases (1). Assessment of RV function is challenging because of its complex crescent shaped geometry and load conditions being significantly influenced by respiration. Incremental insights into RV blood flow patterns have the potential to add to our understanding of RV function (2), but remain incompletely characterized.

\section{Hypothesis}

We hypothesized that a specific portion of the RV enddiastolic (ED) blood volume is prepared for effective systolic ejection and that this sub-volume can be identified based on its pre-systolic kinetic energy (KE) and location.

\section{Method}

Three-directional, 3-dimensional cine phase-contrast CMR velocity-data and morphological bSSFP images were acquired on a $1.5 \mathrm{~T}$ scanner (Philips Achieva) in ten healthy subjects ( 4 female, aged $46 \pm 17$ years [mean \pm SD]). A previously validated method was used for the flow analysis (3): The RV endocardium was segmented (http://segment.heiberg.se) from the morphological images at ED and end-systole (ES). Pathlines were emitted from the ED blood volume and traced forward and backward in time until ES. Accordingly, the ED blood volume could be automatically separated into four functional flow components $(3,4)$ (Figures 1 and 2). By the volume occupied by each trace, its velocity and the density of blood, the kinetic KE was calculated throughout the cardiac cycle.

${ }^{1}$ Center for Medical Image Science and Visualization (CMIV), Linköping University, Linköping, Sweden

Full list of author information is available at the end of the article

\section{Results}

The portion of RV inflow passing directly to outflow (Direct Flow), possessed a larger pre-systolic KE than the other three flow components $(\mathrm{p}<0.01)$ (Figure 3$)$. The Direct Flow had a larger volume than the other flow components $(\mathrm{p}<0.001)$, and was located mainly in the basal half of the ventricle (Figures 1 and 2). The Residual Volume was larger than the Delayed Ejection

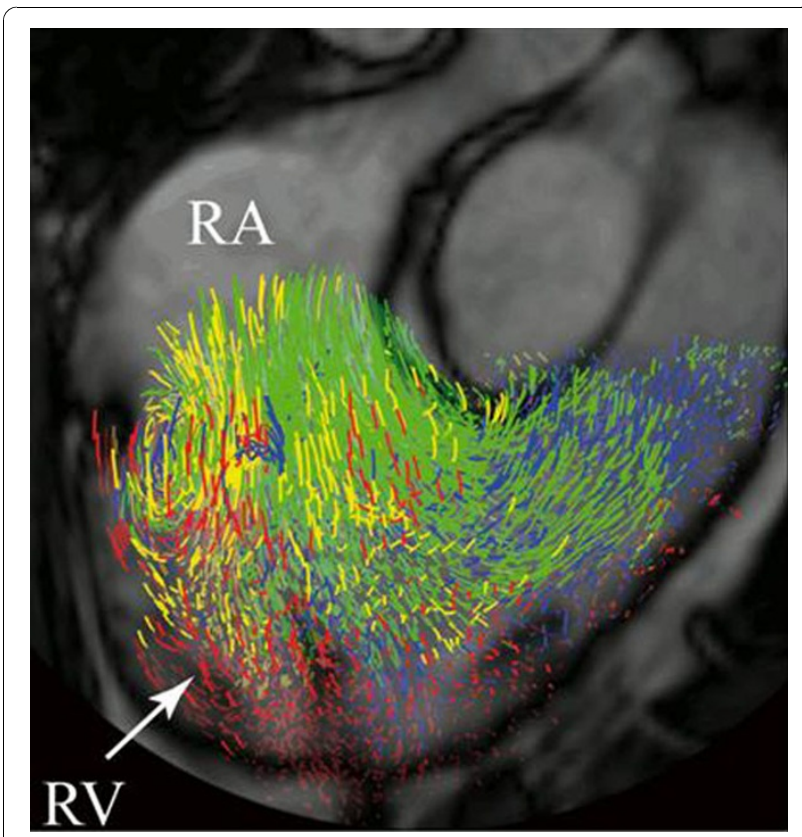

Figure 1 Visualization of right ventricular (RV) flow at end-diastole in a healthy subject. Direct Flow (green), blood that enters and leaves the RV within the analyzed cardiac cycle (CC), Retained Inflow (yellow), blood that enters but does not leave the RV within the analyzed CC; Delayed Ejection Flow (blue), blood that leaves but does not enter the RV within the analyzed CC. RA, right atrium; RV, right ventricle. 


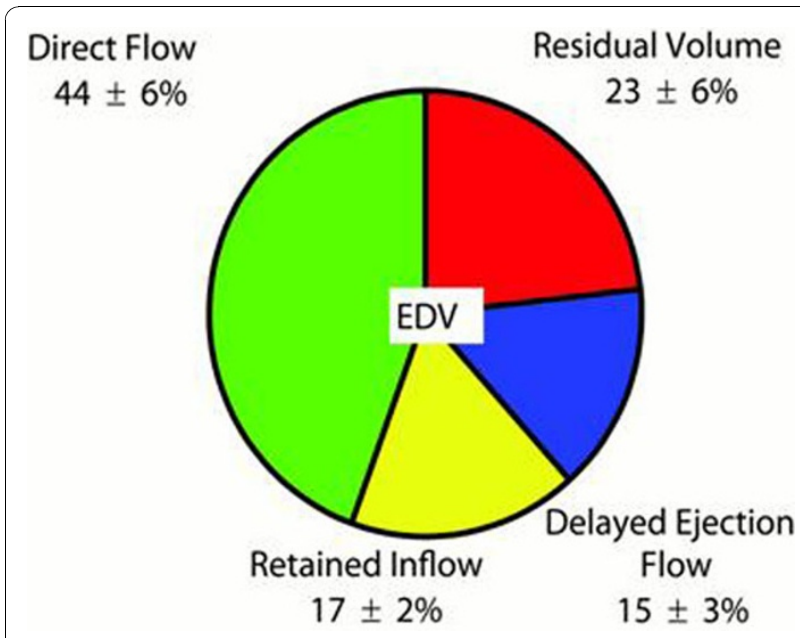

Figure 2 Illustration of the four right ventricular (RV) flow components as a percentage of RV end-diastolic volume (EDV) in healthy subjects.

Flow $(\mathrm{p}<0.01)$ and the Retained Inflow $(\mathrm{p}<0.05)$, and was located mainly in the apical half of the ventricle (Figures 1 and 2).

\section{Conclusions}

Semi-automatic analysis of 4D CMR velocity data allows separation of RV flow into distinct functional components. The present findings suggest that diastolic flow in the normal RV creates favorable conditions for effective systolic ejection, defined by pre-systolic KE and location, for the Direct Flow component. These flow-specific aspects of RV diastolic-systolic coupling may provide new useful perspectives on RV- and interventricular function in health and disease.

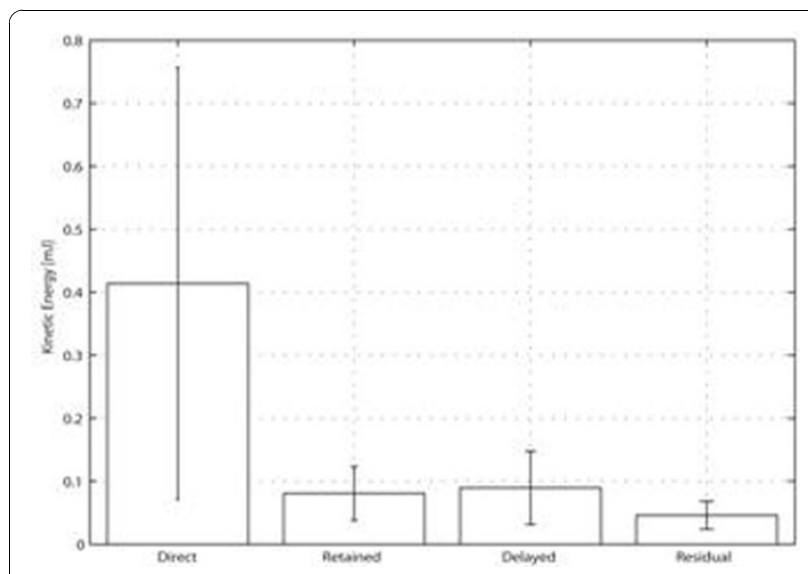

Figure 3 End-diastolic kinetic energy for the four right ventricular flow components in healthy subjects.

\section{Author details}

${ }^{1}$ Center for Medical Image Science and Visualization (CMIV), Linköping University, Linköping, Sweden. ${ }^{2}$ University of California San Francisco, San Francisco, CA, USA.

Published: 2 February 2011

\section{References}

1. Haddad R, et al: Circ 2008, 117:1717-31.

2. Kilner $P$, et al: Nature 2000, 404:759-61.

3. Eriksson J, et al: JCMR 2010, 12:9.

4. Bolger AF, et al: JCMR 2007, 9:741-47.

doi:10.1186/1532-429X-13-S1-083

Cite this article as: Carlhäll et al:: Visualization and quantification of 4D blood flow distribution and energetics in the right ventricle. Journal of Cardiovascular Magnetic Resonance 2011 13(Suppl 1):083.
Submit your next manuscript to BioMed Central and take full advantage of:

- Convenient online submission

- Thorough peer review

- No space constraints or color figure charges

- Immediate publication on acceptance

- Inclusion in PubMed, CAS, Scopus and Google Scholar

- Research which is freely available for redistribution

Submit your manuscript at www.biomedcentral.com/submit
C Biomed Central 